\title{
Evaluation of Sodium Diclofenac Release Using Natural Rubber Latex as Carrier
}

\author{
Patricia B. Aielo ${ }^{a}$, Felipe A. Borges ${ }^{a}$, Karoline M. Romeira ${ }^{a}$, Matheus Carlos Romeiro Miranda ${ }^{b}$ \\ Larisa B. de Arruda , Paulo Noronha L. Filho ${ }^{c}$,Bruno de C. Drago ${ }^{c}$, Rondinelli D. Herculano ${ }^{*}$ \\ ${ }^{a}$ Departamento de Ciências Biológicas, Faculdade de Ciências e Letras de Assis, \\ Universidade Estadual Paulista - UNESP, Assis, SP, Brazil \\ ${ }^{b}$ Instituto de Química, Universidade Estadual Paulista - UNESP, CEP14800-060, Araraquara, SP, Brazil \\ 'Departamento de Física, Faculdade de Ciências, Universidade Estadual Paulista - UNESP, Bauru, SP, Brazil
}

Received: April 12, 2013; Revised: December 4, 2013

\begin{abstract}
Sodium Diclofenac is a non-steroidal anti-inflammatory drug (NSAID) taken to reduce inflammation and, as an analgesic, reduce pain. Although this drug is widely used in the general population, properties such as the short half-time and some side effects restrict its clinical use. The most common side effects are: gastric irritation, gastritis, peptic ulcer and bleeding. Studies involving biomaterials as carrier for drug release have been proving their efficiency in overcoming those problems and better controling the release rate and targeting of the drug. Natural rubber latex (NRL) has been proven excellent for its biocompatibility and ability to stimulate angiogenesis, cellular adhesion and the formation of extracellular matrix, promoting the replacement and regeneration of tissue. In this work, a NRL membrane is used to deliver sodium diclofenac. Sodium diclofenac (NaDic) was found to be adsorbed on the NRL membrane, with little or no incorporation into the membrane bulk, according to energy dispersive Scanning Electron Microscopy with X-Ray microanalysis (SEM-EDS) spectroscopy. In addition, FT-IR shows that there is no molecular-level interaction between drug and NRL. Already, the X-Ray Diffraction (XRD) of NaDic-NRL shows a broader one spectrum than the sharper halo (amorphous characteristic XRD spectrum) of pure NRL. More importantly, the release time of diclofenac in a NRL membrane in vitro was increased from the typical 2-3 $\mathrm{h}$ for oral tablets to ca. $74 \mathrm{~h}$. The kinetics of the drug release could be fitted with a double exponential function, with two characteristic times of 0.899 and 32.102 h. In this study, we demonstrated that the interesting properties provided by NRL membranes combined with a controlled release of drug is relevant for biomedical applications.
\end{abstract}

Keywords: membranes, natural rubber, sodium diclofenac, drug delivery system, biomaterials

\section{Introduction}

Diclofenac sodium $(\mathrm{NaDic})$ is a non-esteroidal antiinflammatory, analgesic and antipiretic drug (NSAID) (Figure 1). It is a sodium salt of an aminophenyl acetic acid $^{1}$ which is rapidly absorbed after oral administration, having a short biological half-time between 1-2h and high

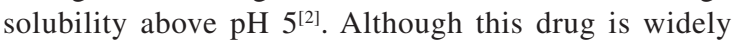
used in the treatment of tendinitis, rheumatoid arthritis, osteoarthritis and ankylosing spondylitis, properties such as the short half-time and some side effects restrict its clinical use $^{1}$. The most common side effects are: gastric irritation, gastritis, peptic ulcer and bleeding ${ }^{3}$. Recent researches are being developed to improve drug release such as use of tabletted microspheres ${ }^{2}$, acetate butyrate microparticles (a kind of polymer) $)^{3}$, nanoparticles and many other. Studies involving biomaterials as carrier for drug release have been proving their efficiency in overcoming those problems and better controling the release rate and targeting of the drug.

When drugs are injected intravenously only one part in ten thousand reaches its final target, in appropriate concentrations to cause the expected therapeutic effect ${ }^{5,6}$.

*e-mail: rond@assis.unesp.br
This proportion is due to many anatomical, chemical and biological obstacles verified between the local administration of the drug and the target organ or tissue.

Therefore controlled drugs release is an important pharmacology subject. This technique can provide the creation of optimized systems that ensure the controlled release of these drugs to a specific site.

One candidate already described in literature ${ }^{7-11}$ as a potential carrier is the natural rubber latex (NRL) from Hevea brasiliensis. The NRL membrane is an important inductor of the healing process of wounds, being used in several medical applications like prosthetics and bone grafts $^{12-16}$. In addition, the treatment of diabetic and phlebopathic ulcers with these membrane leads to a faster healing process due to a vascular growth factor found in the latex and due to a physical blockage of the entrance of new infectious agents in the treated site ${ }^{17,18}$. NRL membrane has some interesting characteristics such as: easy manipulation, low cost, can stimulate natural angiogenesis and cellular adhesion, is a biocompatible material and presents high mechanical resistance ${ }^{19,20}$. The aggregation of sodium diclofenac in drug-delivery systems (DDS) aimed at drug- 


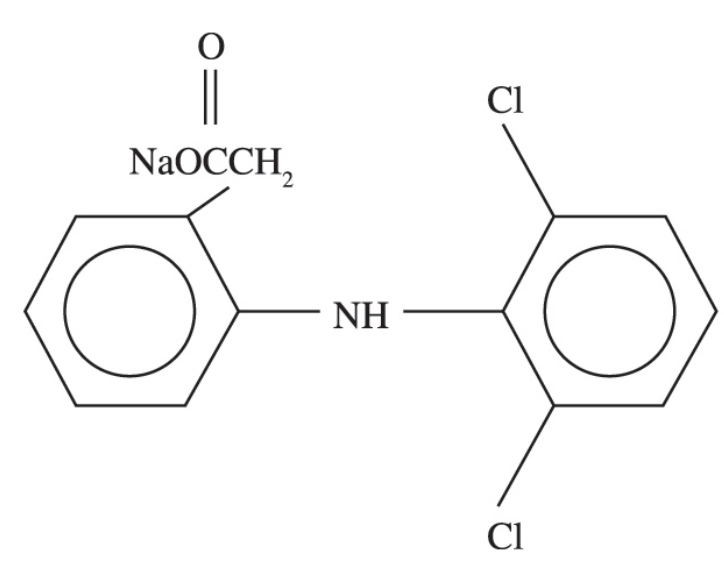

Figure 1. Molecular structure of sodium diclofenac ${ }^{4}$.

membrane interaction, for further optimization of the located anti-inflamation, avoiding some complications.

In this work, it is propose a novel release system based on the encapsulation of diclofenac in NRL membrane for a sustained and controlled delivery of the drug, possibly being a future application in medicine as surgical bandage for bone and tissue regeneration. Results showed that the NRL membrane can release sodium diclofenac for up to 74 hours. In addition, the X-Ray Diffraction (XRD) and Scanning Electron Microscopy with X-Ray microanalysis (SEM-EDS) showed that sodium diclofenac properties and structure are preserved while incorporated in the membrane, which is relevant for possible biomedical applications. FTIR spectra shows that there is no molecular-level interaction between drug and NRL. More importantly, the release time of sodium diclofenac in a NRL membrane in vitro was increased from the typical 1-2 h for oral tablets to ca. 74 h. The kinetics of the drug release could be fitted with a double exponential function, with two characteristic times of 0.899 and $32.102 \mathrm{~h}$.

\section{Material and Methods}

Natural rubber latex (NRL) used in the present study was commercial high-ammonia natural rubber latex (BDF Latex, Guarantã/SP, Brazil) of about $60 \%$ dry rubber content (DRC). After extraction, ammonia was used to keep the latex liquid. NRL was performed by centrifugation at 8,000 $\mathrm{g}^{[7,8]}$ to reduce the protein content related with allergies.

Sodium diclofenac $\left(\mathrm{C}_{14} \mathrm{H}_{11} \mathrm{Cl}_{2} \mathrm{NO}_{2}\right)$ was purchased from CALLITHEA Pharmaceutics Ltd., Brazil. Diclofenac was incorporated by mixing $6 \mathrm{~mL}$ of natural rubber latex with $3 \mathrm{~mL}$ of diclofenac solution $\left(3 \mathrm{mg} \cdot \mathrm{mL}^{-1}\right)$. These membranes were prepared by pouring the latex + diclofenac solution in a stainless steel plate with $5.00 \pm 0.05 \mathrm{~cm}$ diameter and $234.40 \pm 5.00 \mu \mathrm{m}$ thick. Typically, the membranes were left for 2 days to fully polymerize before use. For the study of the diclofenac release, latex membranes were placed in $300 \mathrm{~mL}$ of an aqueous solution in triplicate, from which aliquots were collected during an interval ranging from 0 to 250 hours. The diclofenac released into the solution was monitored by measuring the UV-VIS spectra with a
BEL ENGINEERING SF200 ADV spectrophotometer, as diclofenac has a maximum absorption at $276 \mathrm{~nm}$.

The membranes were characterized by X-ray powder diffraction (XRD), using a Siemens D5005 X-ray diffractometer and a graphite crystal as monochromator to select $\mathrm{Cu} \mathrm{K \alpha} 1$ radiation $\left(1.5406 \AA\right.$ ), in a step of $0.02^{\circ} \mathrm{s}^{-1}$. The surface morphology of the NRL membrane was observed using a Scanning Electron Microscopy (SEM) model Zeiss ${ }^{\circledR}$ EVO $50(20 \mathrm{KV})$ and a take off angle of $35^{\circ}$.

The FT-IR spectra of the pure diclofenac, Natural Rubber Latex (NRL) and NRL + diclofenac (3 mg.mL $\left.{ }^{-1}\right)$ were obtained to prove the chemical integrity of the drug in the polymer. The samples were measured directly by Attenuated Total Reflection (ATR) method, which is an excellent method for obtaining infrared information for the powder sample surface. The membranes were characterized using a VERTEX 70 (Bruker, Germany) (4000-500 cm-1) with a resolution of $4 \mathrm{~cm}^{-1}$.

In Figure 2 shows the absorbance intensity as a function of diclofenac concentration in solution. This calibration curve is important because to make one relationship between absorbance and the diclofenac concentration. For this experiment several dciclofenac concentrations from 0.01 to $0.1 \mathrm{mg} . \mathrm{mL}^{-1}$ were made. After this, it was measurement your absorbance. Each drug concentration (point) were made in triplicate, where the estimated error was minor that $5 \%$.

\section{Results and Discussion}

The goal of controlled-release delivery systems is to provide desirable delivery patterns so that predictable plasma drug levels can be achieved, which requires the characterization of the basic pharmacodynamic and pharmacokinetic properties of a drug/extract. For sodium diclofenac studied here, it has been found that it absorbs at $276 \mathrm{~nm}$.

As can be seen in Figure 3, the absorbance intensity of diclofenac increase in function as time. We can observed that diclofenac is encapsulated in natural latex membranes, where the NRL membrane allows a gradual release of diclofenac from the aqueous solution. We observed that the release profiles for sodium diclofenac in a NRL matrix is similar from our previous work ${ }^{8}$, but the saturation point is different and the inclination of bi-exponential function. In this work, the points to saturation at approximately 74 hours. Its release control can be due biomembrane hydrophobicity ${ }^{21}$.

These results were also obtained by Giri et al. ${ }^{22}$ which acrylic acid grafted guargum-nanosilica biomembrane provided excellent control over diclofenac releases, as well as by Pulat et al. ${ }^{23}$ that showed that PU (hydrophobic) membranes had a slower release than hydrophilic ones. This may be due hydrophobic membranes do not lead to void volume between molecules, hampering the diffusion through membrane.

In this work, it was used the method proposed by Herculano et al. ${ }^{24}$, that is, to mix the drug (diclofenac) with the polymer (latex) in a colloidal state, in order to create a membrane that works as a delivery system.

Upon analyzing the profiles, we concluded that the first, fast step of burst release corresponded to the diclofenac near 


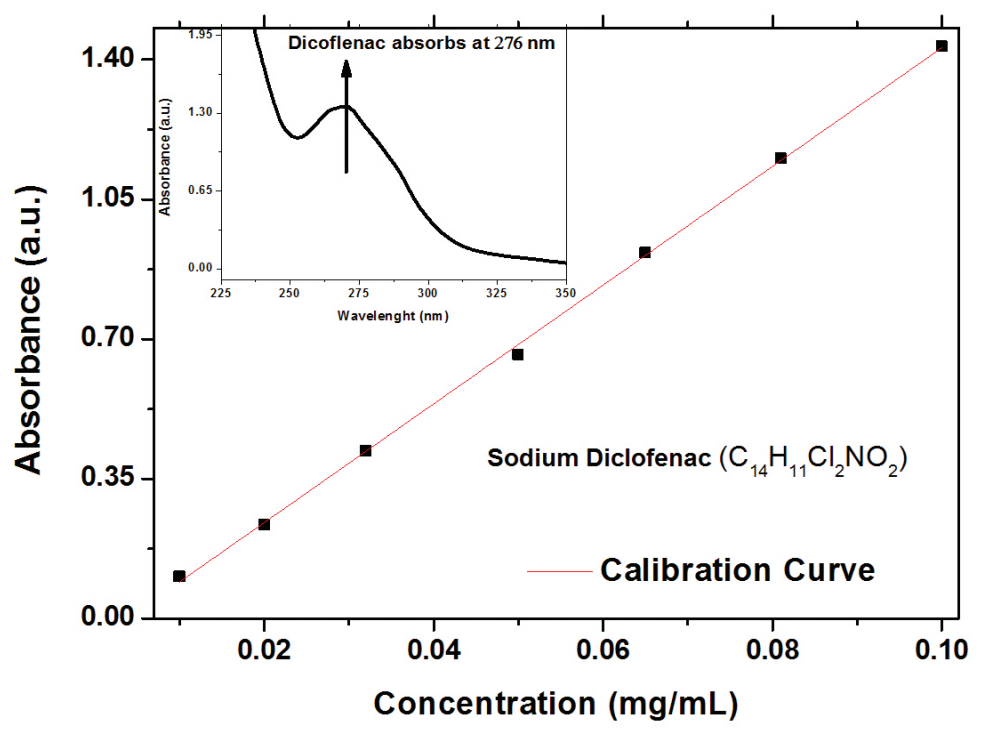

Figure 2. Absorbance instensity as a function of sodium diclofenac concentration in solution. Notice that the insert graph shows a typical spectrum of sodium diclofenac.

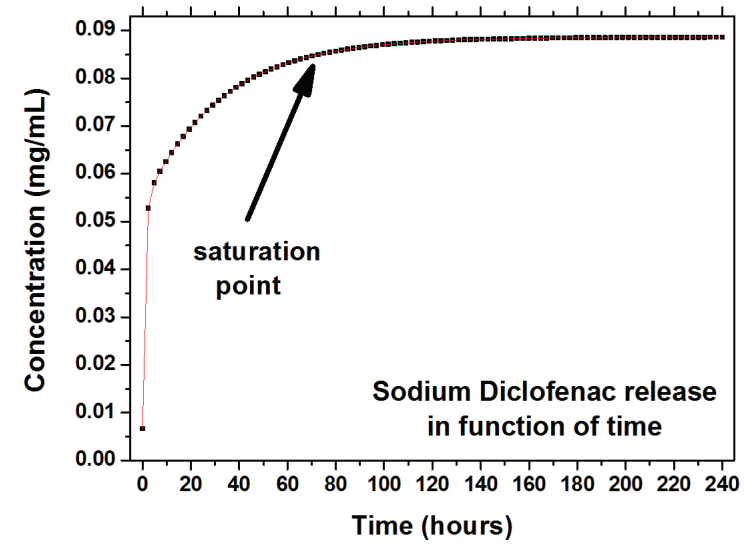

Figure 3. Sodium diclofenac release as a function of time for the NRL membrane. Notice that the diclofenac concentration reaches a plateau after approximately 74 hours. Each point refers to triplicate measurement.

or on the surface of the NRL membrane. Therefore, the slower release process would be associated with diclofenac diffusing slowly through the matrix. The experimental data in the Figure 3 were fitted using a bi-exponential function (A). $y(t)=y_{0}+A_{1} e^{-t / \tau 1}+A_{2} e^{-t / \tau 2}$, where, $y(t)$ was the amount of sodium diclofenac in the NRL at a given time, $t, y_{0}$ is the initial content of diclofenac, $\mathrm{A}_{1}$ and $\mathrm{A}_{2}$ are constants, equal to -0.047 and -0.035 , respectively, the characteristic times are $\tau_{1}=0.899$ hours and $\tau_{2}=32.102$ hours.

Upon integrating the curve until $74 \mathrm{~h}$, the total amount of diclofenac released by the membrane in the $300 \mathrm{~mL}$ aqueous solution was $5.37 \mathrm{mg}(59.62 \%)$.

The X-ray diffraction (XRD) pattern for the NRL membrane, sodium diclofenac powder $(\mathrm{NaDic})$ and NRL membrane prepared with $3 \mathrm{mg} \cdot \mathrm{mL}^{-1}$ of sodium diclofenac (NaDic-NRL) is shown in Figure 4, which indicates the amorphous nature of NRL, as expected, at $19^{\circ}$ at $2 \theta^{[21]}$. In

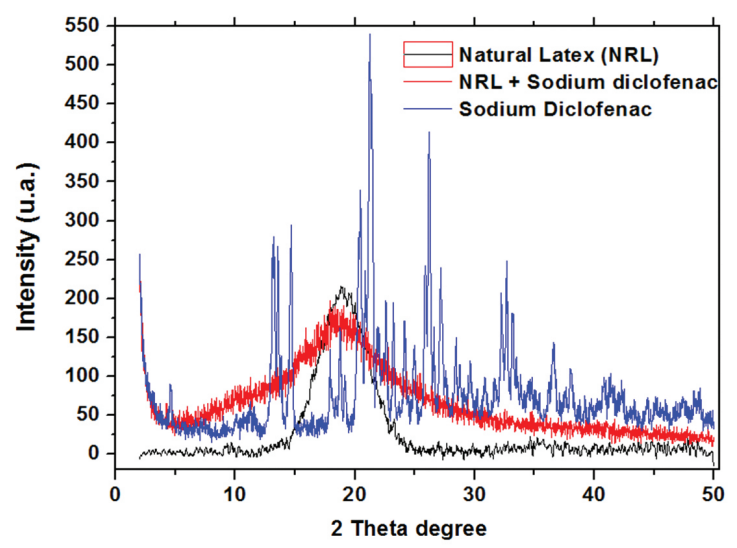

Figure 4. X-ray diffraction pattern of NRL (black line), sodium diclofenac powder (blue line), NRL membrane prepared with 3 $\mathrm{mg} \cdot \mathrm{mL}^{-1}$ of sodium diclofenac (red line).

contrast, sodium diclofenac powder exhibits a XRD pattern of a crystalline material with no amorphous component, with peaks appearing at $14.70,20.48,25.96,26.40$ and $27.20^{\circ}$ at $2 \theta$ values $^{25}$. The absence of crystallinity in the NaDic-NRL membrane indicates that $\mathrm{NaDic}$ is amorphous or molecularly disperse within the microparticles ${ }^{25,26}$.

Amorphous NaDic has also been found by Li et al. ${ }^{27}$, Manjunatha et al. ${ }^{28}$, Lopes et al. ${ }^{29}$ and Maiti et al. ${ }^{30}$ showed barely irritant to rat skin.

Although NaDic-NRL shows a broader XRD spectrum than the sharper halo (amorphous characteristic XRD spectrum) of pure NRL, FT-IR shows that there is no chemical interaction between NaDic and NRL, since there is no new absorption peaks.

The IR spectra of the sodium diclofenac, natural rubber latex (NRL) and NRL + diclofenac are portrayed in Figures 5, 6 and 7. The IR spectra of diclofenac sodium 
(Figure 5) exhibited distinctive peaks at $3381.57 \mathrm{~cm}^{-1}$ due to $\mathrm{NH}$ stretching of the secondary amine, $1572.66 \mathrm{~cm}^{-1}$ owing to $-\mathrm{C}=\mathrm{O}$ stretching of the carboxyl ion and at $745.35 \mathrm{~cm}^{-1}$ because of $\mathrm{C}-\mathrm{Cl}$ stretching ${ }^{27}$.

FT-IR spectra of natural rubber is presented in Figure 6. The cis-1,4-polyisoprene absorption band of strong amplitude corresponding to $=\mathrm{CH}$ out of plane

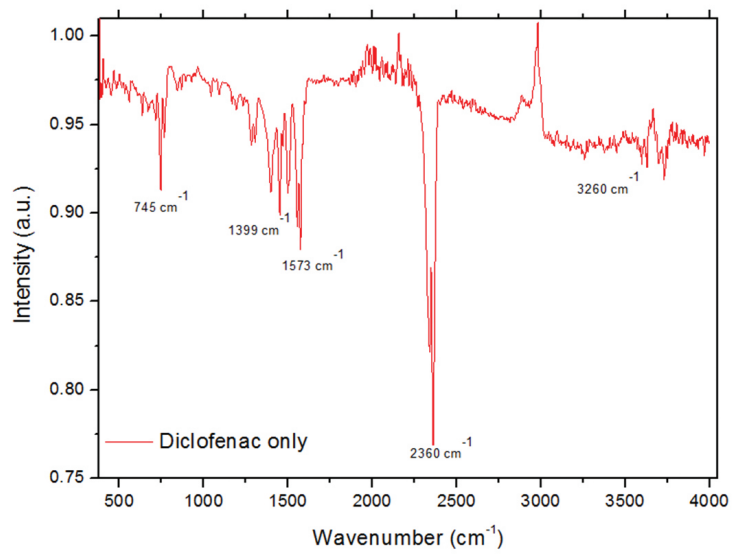

Figure 5. FT-IR spectra of sodium diclofenac in ATR method.

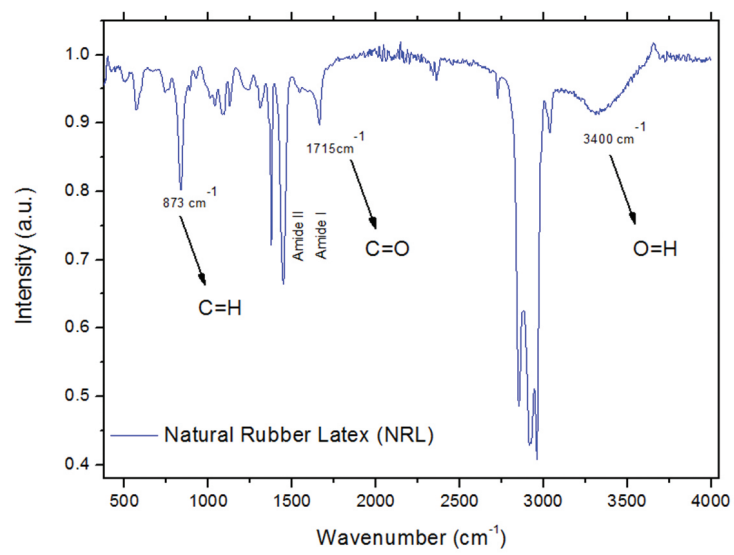

Figure 6. FTIR spectra of natural rubber membranes in ATR method.

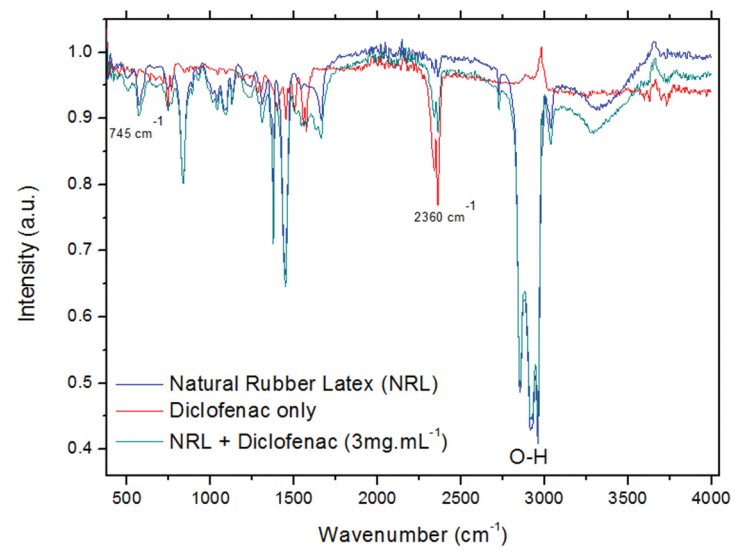

Figure 7. FTIR spectra after of incorporation of sodium diclofenaci in natural rubber membranes. bending is observed at $873 \mathrm{~cm}^{-1}$; the trans isomer has no absorption at this wavelength. A closer inspection of the infrared spectra reveals that it has absorbance bands at $1240 \mathrm{~cm}^{-1}$, corresponding to O-P-O asymmetric stretching of phospholipids indicating the presence of associated phospholipids at the rubber chain.. The absorptions bands at $1375 \mathrm{~cm}^{-1}$ (CH deformation), $1394 \mathrm{~cm}^{-1}$ and $1432 \mathrm{~cm}^{-1}$ and $1494 \mathrm{~cm}^{-1}$ are characteristics of $\mathrm{CH}_{2}$ deformation. The absorption band at $1647 \mathrm{~cm}^{-1}$ correspond to $\mathrm{C}=\mathrm{C}$ stretching in cis-1,4-polyisoprene. The $\mathrm{CH}_{2}$ symmetric stretching vibrations are observed at the region $2852 \mathrm{~cm}^{-1}-2925 \mathrm{~cm}^{-1}$. The $\mathrm{CH}_{3}$ asymmetric stretching in FT-IR of NRL membranes is observed at $2961 \mathrm{~cm}^{-1}$. These FT-IR correlations for NRL are consistent with the earlier works ${ }^{24,31}$. In addition, Figure 6 also shows a broad peak at approximately $3200-3500 \mathrm{~cm}^{-1}$. This absorption band might be related to the presence of a hydroxyl group, which appears to be generated after the hydrolytic ring opening of epoxy group 's formed during the casting of NRL membranes ${ }^{24,32}$.

In the IR spectra of the polymer and drug (Figure 7) was not altered after immobilization in the latex membrane, indicating no chemical interaction between the drug and the polymer.

Figure 8a is an SEM-EDS image of the sodium diclofenac powder (NaDic) and Figure $8 b$ is SEM-EDS of Natural rubber membrane + sodium diclofenac (NaDicNRL). Notice that sodium diclofenac is aggregated in surface polymer reinforcing that burst release corresponded to the drug on the surface of the NRL membrane.

The controlled release of drug is of interest for medical applications, since the dose can be adjusted according to the necessity of the patient. Löbler et al. ${ }^{33}$ developed a device based in polyhydroxyalkanoates (PHA) for implantation of a glaucoma drainage system. In this study, polyhydroxyalkanoates (PHA) based on hydroxybutyric acid were tested in terms of their potential suitability to manufacture mechanically stable tube components of drug delivery drainage systems and in terms of biocompatibility.

Several procedures are used to control the release of substances by polymers. For example Woo et al. ${ }^{34}$ used a combination of 3 different biodegradable microspheres of poly(D,L,-lactide-co-glycolide (PLGA)), using different molecular weight and terminal endings of the polymeric chain (hydrophilic or hydrophobic) to determine the best delivery system of BMP. They conclude that the best bone healing results were achieved using high dose and slow delivery rate systems.

Herculano et al. ${ }^{7,8,35}$ proposed a drug release system based on natural rubber latex (NRL) for the sustained and controlled delivery of metronidazole (MET), Bovine Serum Albumine (BSA) and Stryphnodendron $s p$ extract. They concluded that the release time of MET, BSA and Stryphnodendron $s p$ in in vitro tests were very promising for the kinetics of release.

Wang et al. ${ }^{36}$ prepared uniform-sized chitosan microspheres by membrane emulsification technique. Uniform chitosan microspheres were further used as a carrier of protein drug (BSA). They observed that BSA loading efficiency was highest when $\mathrm{pH}$ value was 8.09, and it decreased with an increase of the crosslinking degree. 


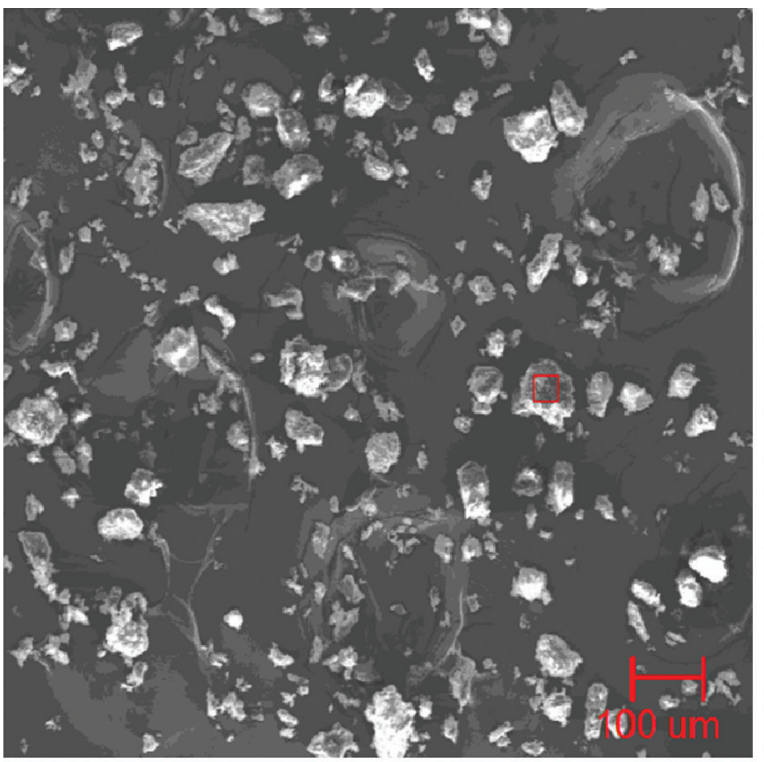

(a)

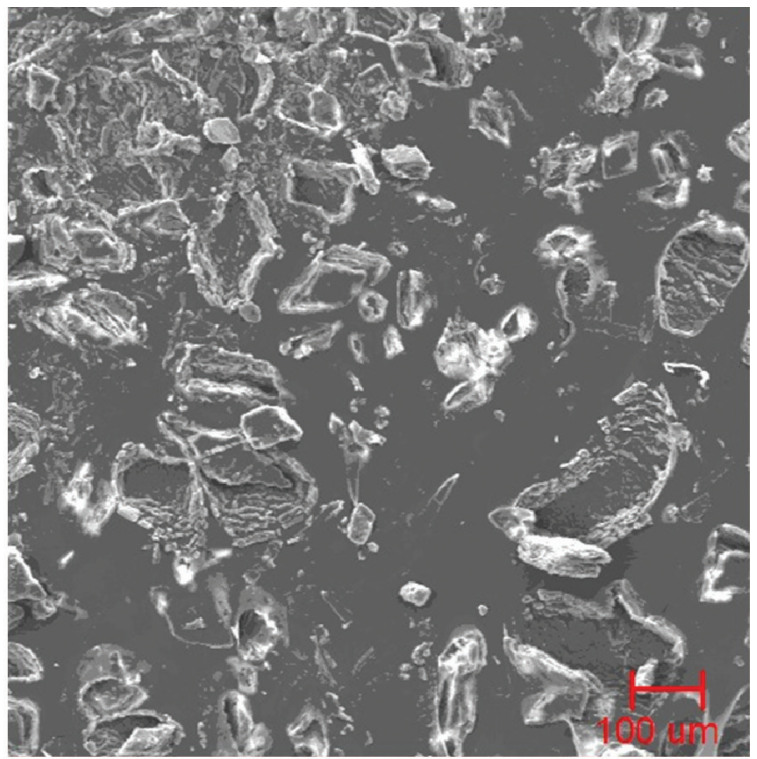

(b)

Figure 8. SEM-EDS of spectra of: a) Sodium diclofenac powder; b) Natural rubber membrane + sodium diclofenac. Notice that the diclofenac is present on surface.

Some biomaterial have been developed to diclofenac delivery. Guargum (natural polymer) have showed good diclofenac delivery, it showed a fast release, $81 \%$ of the content in 20 hours; but the acrylic acid grafted guargumnanosilica membrane showed a slower release due its hydrophobicity $^{22}$. Biomembranes of polyethylene glycol 400 (PEG 400) with hydroxypropylmethylcellulose (HPMC) for ophthalmic uses with diclofenac-loaded particles released $50 \%$ in 12 hours $^{37}$

The release time of sodium diclofenac in a NRL membrane in vitro was increased from the typical $1-2 \mathrm{~h}$ for oral tablets to ca. $74 \mathrm{~h}$. Our results indicate that with very simple changes in preparation of NRL membrane, $59.62 \%$ of the initial diclofenac content inside NRL was released in 3 days, with a slow release rate.

\section{Conclusion}

It has been demonstrated that diclofenac can be encapsulated in NRL membranes, lying mostly on the membrane surface, as inferred from energy dispersive
X-ray spectroscopy. FTIR indicate that NaDic did not interact chemically with the membrane. The XRD shows the absence of crystallinity in the NaDic-NRL membrane indicates that $\mathrm{NaDic}$ is amorphous or molecularly disperse within the microparticles.

Results indicate that with very simple latex preparation it is possible to control diclofenac release up to 3 days, or in other words with a slow release rate.

We have observed that $59.62 \%$ of the initial diclofenac content inside NRL was released in 74 hours. The SEMEDS and the release behavior indicated that diclofenac remains close or on the surface of the membrane. The drug is not found in the inner portion of the membrane, thus making them promising materials for drug release in in vivo applications

\section{Acknowledgements}

This work was supported by PROPe/UNESP, CNPq/ PIBIC, FUNDUNESP (Process: 193/2011) and FAPESP (Process: 2011/17411-8).

\section{References}

1. Tunçay M, Cali S, Ka HS, Ercan MT, Peksoy I and Hincal AA. In vitro and in vivo evaluation of diclofenac sodium loaded album in microspheres. Journal Of Microencapsulation. 2000; 17(2):145-155. http://dx.doi.org/10.1080/026520400288382

2. Gürsoy A and Cevik S. Sustained release properties of alginate microspheres and tabletted microspheres of diclofenac sodium. Journal Of Microencapsulation. 2000; 17(5):565-575. http:// dx.doi.org/10.1080/026520400417621

3. Barakat NS and Ahmad AA. Diclofenac sodium loadedcellulose acetate butyrate: Effect of processing variables on microparticles properties, drug release kinetics and ulcerogenic activity. Journal Of Microencapsulation. 2008; 25(1):31-45. http://dx.doi.org/10.1080/02652040701747928

4. Cursarua B, Teodorescua B, Boscorneaa C, Stanescua PO and Stoleriub S. Drug absorption and release properties of crosslinked hydrogels based on diepoxy-terminated poly(ethylene glycol)s and aliphatic polyamines — a study on the effect of the gel molecular structure. Materials Science and Engineering: C. 2013; 3(1):1307-1314. http://dx.doi. org/10.1016/j.msec.2012.12.030

5. Brazeau GA, Cooper B, Svetic KA, Smith CL and Gupta P. Current perspectives on pain upon injection of drugs. Journal of 
Pharmaceutical Sciences. 1998; 87(6):667-677. http://dx.doi. org/10.1021/js9703151

6. Brazeau GA and Fung HL. An in vitro model to evaluate muscle damage following intramuscular injections. Pharmaceutical Research. 1989; 6(2):167-170. http://dx.doi. org/10.1023/A:1015940811827

7. Herculano RD, Pereira CP, Ereno C, Catanzaro GSAC, Kinoshita A and Graeff CFO. Natural rubber latex used as drug delivery system in guided bone regeneration (GBR). Materials Research. 2009; 12(2):253-256. http://dx.doi.org/10.1590/ S1516-14392009000200023

8. Herculano RD, Guimarães SAC, Belmonte GC, Duarte MAH, Oliveira-Júnior ON, Kinoshita $S$ et al. Metronidazole release using natural rubber latex as matrix. Materials Research. 2010; 13(1):57-61. http://dx.doi.org/10.1590/S151614392010000100013

9. Herculano RD, Brunello CAA and Graeff CFO. Optimization of a novel Nitric Oxide Sensor using a latex rubber matrix. Journal of Applied Sciences. 2007; 7(23):3801-3805. http:// dx.doi.org/10.3923/jas.2007.3801.3805

10. Herculano RD, Tzu LC, Silva CP, Brunello CA, Queiroz AAA, Kinoshita A et al. Nitric oxide release using natural rubber latex as matrix. Materials Research. 2011; 14(3):355-359. http:// dx.doi.org/10.1590/S1516-14392011005000055

11. Herculano RD, Brunello CA and Graeff CFO. Solid state Nitric Oxide sensor using a latex rubber matrix. Macromolecular Symposia. 2006; 245-246(1):529-532. http:// dx.doi.org/10.1002/masy.200651376

12. Ciapetti G, Stea S, Pizzoferrato A, Checchi L and Pelliccioni GA. A latex membrane, as an alternative device in the GTR technique: preliminary report on its biocompatibility. Journal of Materials Science: Materials in Medicine. 1994; 5(9-10):647650. http://dx.doi.org/10.1007/BF00120348

13. Ereno C, Guimarães SA, Pasetto S, Herculano RD, Silva CP, Graeff CF et al. Latex use as an occlusive membrane for guided bone regeneration. Journal of Biomedical Materials Research. 2010; 95(3):932-939. http://dx.doi.org/10.1002/jbm.a.32919

14. Mendonça RJ and Coutinho-Netto J. Cellular aspects of wound healing. Anais Brasileiros de Dermatologia. 2009; 84(3):257-262.

15. Ferreira M, Mendonça RJ, Coutinho NJ and Mulato M. Angiogenic properties of natural rubber latex biomembranes and the serum fraction of Hevea brasiliensis. Brazilian Journal of Physics. 2009; 39:564-569. http://dx.doi.org/10.1590/S010397332009000500010

16. Frade MAC, Valverde RV, Assis RVC, Coutinho NJ and Foss NT. Chronic phlebopathic cutaneous ulcer: a therapeutic proposal. International Journal of Dermatology. 2001; 40(3):237-240. http://dx.doi.org/10.1046/j.13654362.2001.00977-2.x

17. Balabanian CACA, Coutinho NJ, Lamano CTL, Lacerda SA and Brentegani LG. Biocompatibility of natural latex implanted into dental alveolus of rats. Journal of Oral Science. 2006; 48(4):201-205. http://dx.doi.org/10.2334/josnusd.48.201

18. Mrué F, Coutinho NJ, Ceneviva R, Lachat JJ, Thomazini JA and Tambelini H. Evaluation of the biocompatibility of a new biomembrane. Materials Research. 2004; 7(2):277-283. http:// dx.doi.org/10.1590/S1516-14392004000200010

19. Neves JWFP, Ferreira M, Alves MCO, Graeff CFO, Mulato M, Coutinho NJ et al. Influence of fabrication process on the final properties of natural-rubber latex tubes for vascular prosthesis. Brazilian Journal of Physics. 2006; 36(2B):586-591. http:// dx.doi.org/10.1590/S0103-97332006000400021
20. Mendonça RJ, Maurício VB, Teixeira LB, Lachat JJ and Coutinho-Netto J. Increased vascular permeability, angiogenesis and wound healing induced by the serum of natural latex of the rubber tree Hevea brasiliensis. Phytotherapy Research. 2009; 24(5):764-768.

21. Johns J and Rao V. Characterization of natural rubber latex/ chitosan blends. International Journal of Polymer Analysis and Characterization. 2008; 13(4):280-291. http://dx.doi. org/10.1080/10236660802190104

22. Giri A, Bhunia T, Mishra SR, Goswami L, Panda AB, Pal S et al. Acrylic acid grafted guargum-nanosilica membranes for transdermal diclofenac delivery. Carbohydrate Polymers. 2013; 91(2):492-501. http://dx.doi.org/10.1016/j. carbpol.2012.08.035

23. Pulat M and Akdo an A. The diffusion and bulk properties of polyurethane (PU) -based hydrophilic and hydrophobic membranes. Journal of Applied Polymer Science. 2002; 85(1):193-198. http://dx.doi.org/10.1002/app.10596

24. Herculano RD, Queiroz AAA, Kinoshita A, Oliveira ON Jr and Graeff CFO. On the release of metronidazole from natural rubber latex membranes. Materials Science \& Engineering C. 2011; 31(2):272-275. http://dx.doi. org/10.1016/j.msec.2010.09.007

25. Shivakumar HN, Desai BG and Deshmukh G. Design and optimization of diclofenac sodium controlled release solid dispersions by response surface methodology. Indian Journal of Pharmaceutical Science. 2008; 70(1):22-30. http://dx.doi. org/10.4103/0250-474X.40327

26. Beck RCR, Lionzo MIZ, Costa TMH, Benvenutti EV, Ré MI, Gallas MR et al. Surface morphology of spray-dried nanoparticle-coated microparticles designed as an oral drug delivery system. Brazilian Journal of Chemical Engineering. 2008; 25(2):389-398. http://dx.doi.org/10.1590/S010466322008000200016

27. Li X, Zhang Z, Li J, Sun S, Weng Y and Chen H. Diclofenac/ biodegradable polymer micelles for ocular applications. Nanoscale. 2012; 4(15):4667-4673 http://dx.doi.org/10.1039/ c2nr30924f

28. Manjunatha KM, Ramana MV and Satyanarayana D. Design and evaluation of diclofenac sodium controlled drug delivery systems. Indian Journal of Pharmaceutical Sciences. 2007; 69(3):384-389. http://dx.doi.org/10.4103/0250-474X.34547

29. Lopes L, Molina EF, Chiavacci LA, Santilli CV, Briois V and Pulcinelli SH. Drug-matrix interaction of sodium diclofenac incorporated into ureasil-poly(ethylene oxide) hybrid materials. RSC Advances. 2012; 2(13):5629-5636. http://dx.doi. org/10.1039/c2ra01216b

30. Maiti S, Kaity S, Ray S and Sa B. Development and evaluation of xanthan gum-facilitated ethyl cellulose microsponges for controlled percutaneous delivery of diclofenac sodium. Acta Pharmaceutica. 2011; 61(3):257-270. http://dx.doi. org/10.2478/v10007-011-0022-6

31. Mohapatra S and Nando GB. Chemical modification of natural rubber in the latex stage by grafting cardanol, a waste from the cashew industry and a renewable. Industrial \& Engineering Chemistry Research. 2013; 52(17):5951-5957. http://dx.doi. org/10.1021/ie400195v

32. Saendee $\mathrm{P}$ and Tangboriboonrat P. Latex interpenetrating polymer networks of epoxidised natural rubber/poly(methyl methacrylate): an insight into the mechanism of epoxidation. Colloid and Polymer Science. 2006; 284(6):634-643. http:// dx.doi.org/10.1007/s00396-005-1437-8

33. Löbler M, Sternberg K, Stachs O, Allemann R, Grabow N, Roock A et al. Polymers and drugs suitable for the development 
of a drug delivery drainage system in glaucoma surgery. Journal of biomedical materials research part $B$ applied biomaterials. 2000; 97B:388-395. http://dx.doi.org/10.1002/ jbm.b.31826

34. Woo BH, Fink BF, Page R, Schrier JA, Jo YW, Jiang $\mathrm{G}$ et al. Enhancement of bone growth by sustained delivery of recombinant human bone morphogenetic protein-2 in a polymeric matrix. Pharmaceutical Research. 2011; 18(12):1747-1753.

35. Romeira KM, Drago BC, Murbach HD, Aielo PB, Silva RMG, Brunello CA et al. Evaluation of Stryphnodendron sp. release using natural rubber latex membrane as carrier. Journal of Applied Sciences. 2012; 12(7):693-697.

36. Wang LY, Ma GH and Su ZG. Preparation of uniform sized chitosan microspheres by membrane emulsification technique and application as a carrier of protein drug. Journal of Controlled Release. 2005; 106(1-2):62-75.

37. El-Sousi S, Nácher A, Mura C, Catalán-Latorre A, Merino V, Merino-Sanjuán M et al. Hydroxypropylmethylcellulose films for the ophthalmic delivery of diclofenac sodium. Journal of Pharmacy and Pharmacology. 2013; 65(2):193-200. 